\title{
Enhancing theory development in marketing
}

\author{
Manjit S. Yadav
}

Received: 3 March 2014 / Accepted: 3 March 2014

(C) Academy of Marketing Science 2014

It is an honor and a privilege to serve as Editor of AMS Review. As I start my term, I would like to discuss my views about the journal, the challenges and opportunities it faces, and its future prospects. I would also like to describe initiatives that build on the efforts of the founding Editors, Vicky Crittenden and Bob Peterson, and the Academy of Marketing Science (AMS). These initiatives, over time, can play an important role in significantly elevating AMS Reviews's stature in the marketing discipline and set the stage for the journal to reach its full potential.

AMS Review aspires to become a premier academic journal that is focused exclusively on conceptual articles in the marketing discipline. It will take time; however, with the support of marketing scholars who wish to elevate our discipline's impact, this aspiration can be realized. The marketing discipline, historically, has had a very healthy appetite for theory development work. Unfortunately, over the past few decades, the discipline's deep-seated tradition of publishing highquality conceptual articles has been broken (MacInnis 2011; Yadav 2010). As a result, there has been a steady decline of conceptual articles published in our major journals.

Recent commentaries suggest that these trends are perhaps emblematic of deeper, more systemic problems in the marketing discipline (see, e.g., Reibstein et al. 2009). Systemic problems necessitate systemic solutions; clearly there are no silver bullets. Although concerted, imaginative efforts are needed on multiple fronts, I believe that a renewed focus on developing impactful theory is essential. $A M S$ Review is uniquely positioned to play an important role in this regard. The journal can rejuvenate interest in crafting conceptual articles and facilitate the growth of a new generation of theory development scholars in our discipline. By accomplishing these goals, the journal has the potential to carve out a very special place for itself in the discipline.

M. S. Yadav $(\bowtie)$

Mays Business School, Texas A\&M University,

College Station, TX 77843-4112, USA

e-mail: yadav@tamu.edu
Of course, before that happens, much remains to be done. My comments below focus on three fundamental issues: (1) the supply of high-quality conceptual articles; (2) the scope of conceptual articles; and (3) initiatives planned for moving forward with AMS Review and enhancing theory development work in marketing.

\section{Supply of high-quality conceptual articles}

One of the most significant challenges AMS Review faces today is the lack of supply of high-quality conceptual manuscripts. This is a serious challenge because the factors contributing to the lack of supply are deeply entrenched and, in some cases, inextricably linked (Yadav 2010; for a broader discussion of knowledge development processes in a discipline, see Darden 1991). To understand these factors and explore possible solutions, Fig. 1 highlights the critical role played in knowledge production by several groups of individuals and/or institutions. A detailed discussion of these factors is beyond the scope of this editorial. However, I will describe a few key factors and how they collectively shape the type of knowledge our discipline produces.

As shown in the figure, the current generation of scholars interacts with the next generation of scholars and produces research for review. After the peer review process, a subset of this research becomes the discipline's (published) knowledge output. A variety of institutional factors - for instance, professional associations and promotion and tenure (P\&T) processes - interact with and influence scholars involved in the knowledge development process. In addition, it is also important to recognize that selected exogenous changes originating outside the discipline's boundary can shape what happens in a discipline. For example, in marketing, technological developments and the increased availability of data has significantly influenced knowledge development processes and outcomes.

Using Fig. 1 as a backdrop, one can see that changing the type of knowledge output - for instance, the relative emphasis on empirical vs. conceptual contributions-requires a 


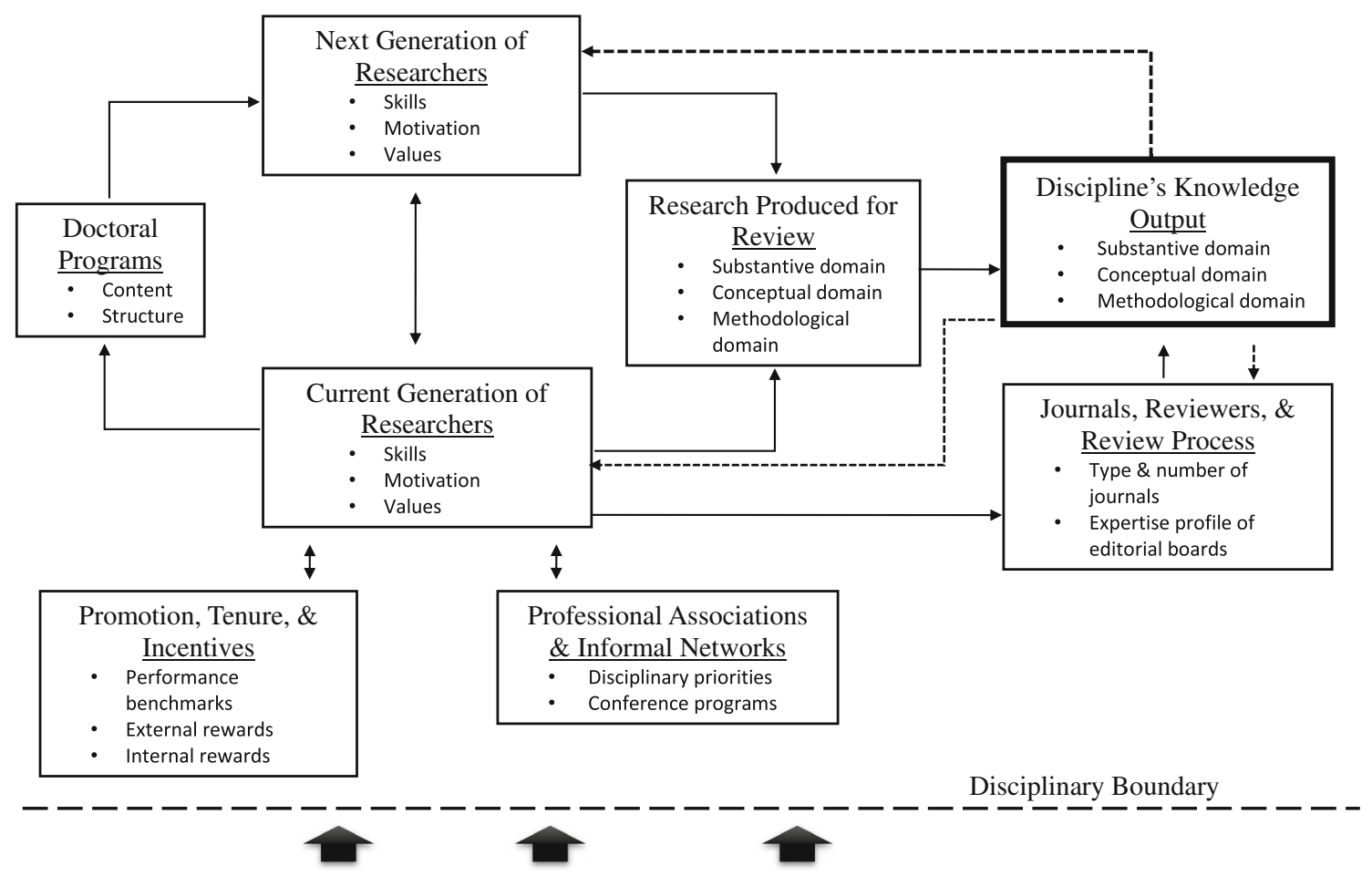

Exogenous Influences on the Discipline

Fig. 1 Determinants of the type of knowledge produced by a discipline

concerted effort in many directions. Among other things, incentive structures for current scholars, review processes, and the structure of doctoral programs may have to be reexamined. One key factor that is particularly relevant for our present discussion regarding AMS Review is the availability of the type and number of journals in a discipline. Simply put, if there is no readily available outlet for a certain type of knowledge output, fewer scholars are likely to produce that type of knowledge. In the marketing discipline, the lack of a highly regarded journal focusing exclusively on conceptual contributions has been a significant institutional impediment. As AMS Review matures, it can fill that void by providing marketing scholars with a premier, well-recognized outlet for contributions that are primarily conceptual in nature.

Figure 1 implies that shifts in knowledge development processes occur slowly in a discipline. This cautious, deliberative approach is actually a desirable feature of disciplines because it insulates them from swaying too readily, or too much, based on passing fads or other short-lived developments. Over the long-term, however, I hope that AMS Review will serve as a catalyst for change and significantly increase the number of high-quality conceptual articles that our discipline produces. I would like to welcome all marketing scholars to be a part of this much-needed change in our field. Figure 1 suggests a number of action items that deserve attention and can serve, collectively, as an agenda for change.

\section{Scope of conceptual articles}

Conceptual articles seek to make theoretical advances without including an empirical component. The primary goal of these articles is theory development, not theory testing. AMS Review focuses exclusively on such articles. However, two important caveats regarding data are worth noting. First, AMS Review welcomes meta-analyses that make theoretical advances based on a quantitative integration of the evidence. Manuscripts can focus on any substantive, conceptual, or methodological issue in the marketing discipline. Given the interdisciplinary nature of marketing, the journal's position statement encourages manuscripts "that integrate research and theory from non-marketing disciplines such as management, sociology, economics, psychology, geography, anthropology, or other social sciences." However, it is imperative that manuscripts establish a clear nexus with one or more issues that are central to the marketing discipline. The second caveat is regarding qualitative data (e.g., in-depth interviews). AMS Review recognizes that qualitative data can, if used judiciously, be useful for purposes of theory building. Such data are particularly useful in the case of emerging phenomena where extant research may be limited. The success of such manuscripts will depend on their ability to combine existing research and qualitative data to advance theory. 
Within this expansive boundary of marketing and selected non-marketing disciplines, authors can craft a wide variety of conceptual articles. MacInnis (2011), in a recent article, describes the numerous possibilities that exist. To develop her taxonomy, MacInnis argues that conceptual articles generally seek to achieve one or more of the following conceptual goals: envisioning, explicating, relating, and debating. "Envisioning" conceptual articles generally identify new phenomena or see an existing phenomenon in a new way. "Explicating" articles delineate an issue or entity and integrate extant knowledge pertaining to that issue or entity. "Relating" articles compare and contrast, highlighting differences and similarities between various components - substantive, conceptual, or methodological — of theory development. "Debating" articles endorse or refute a specific point of view. Furthermore, according to MacInnis, the conceptual goals noted above can be pursued in a number of broad contexts: constructs (measurable theoretical concepts), relationships (linkages between constructs), procedures (methods for conducting research), and domains/disciplines/science (substantive issues in a discipline or other aspects of scientific inquiry).

Building on the arguments presented by MacInnis (2011), Table 1 illustrates the expansive scope of conceptual inquiry that scholars can explore when crafting conceptual articles. Each "cell" in the table should be viewed as a building block for crafting a conceptual article. Depending upon the context, it may be feasible to develop an impactful conceptual paper by focusing on opportunities presented in just one cell. For example, an "envisioning" article that proposes a new construct or rethinks an existing construct can make an important contribution. Such focused conceptual articles, if developed well, are welcome at AMS Review. However, authors are also encouraged to explore combinations of opportunities from various cells in the table. Such combinations have the potential to create even more impactful contributions.

Table 1 shows that the so-called "review article"-which is sometimes (erroneously) viewed as the prototypical conceptual article - represents a relatively small subset of conceptual articles that can be crafted (see the varied options listed in the columns labeled "Explicating" and "Relating"). Conceptual papers that take stock of what has been accomplished in a substantive area and present a comparison/contrast of selected aspects of the evidence can be very useful for guiding further research. However, to make such articles appropriate for $A M S$ Review, authors must also include compelling value-added components that build on the integrative assessment of the literature. Are there any inconsistencies in the evidence? If, so what are some potential theoretical and/or methodological explanations that can account for these inconsistencies? Has a certain facet of the substantive phenomenon received inadequate attention? Does this variation in research attention raise questions about the validity of the cumulative evidence? Of course, many other possibilities exist in this regard; this is where impactful "explicating" conceptual articles really shine.

"Envisioning" conceptual articles break new ground in a number of different ways. Such articles can propose new constructs, advance a set of new relationships, or present a new approach for conducting research. Novel perspectives about a substantive domain - or at the level of the discipline or scientific inquiry — can also represent important conceptual

Table 1 Crafting conceptual articles: scope of inquiry and illustrative examples

\begin{tabular}{|c|c|c|c|c|}
\hline \multirow{2}{*}{$\begin{array}{l}\text { Primary focus/ level of } \\
\text { analysis }\end{array}$} & \multicolumn{4}{|l|}{ Primary conceptual goal } \\
\hline & Envisioning & Explicating & Relating & Debating \\
\hline Constructs & $\begin{array}{l}\text { Propose a new construct or } \\
\text { discuss the need to } \\
\text { rethink an existing } \\
\text { construct. }\end{array}$ & $\begin{array}{l}\text { Present an integrative } \\
\text { discussion of evidence } \\
\text { regarding a focal construct. }\end{array}$ & $\begin{array}{l}\text { Discuss differences } \\
\text { and/or similarities } \\
\text { among a set of } \\
\text { constructs. }\end{array}$ & $\begin{array}{l}\text { Discuss the pros/cons of } \\
\text { the literature's reliance } \\
\text { on a construct. }\end{array}$ \\
\hline Relationship & $\begin{array}{l}\text { Propose new relationships } \\
\text { or rethink existing } \\
\text { relationships. }\end{array}$ & $\begin{array}{l}\text { Present an integrative } \\
\text { discussion regarding } \\
\text { a set of relationships. }\end{array}$ & $\begin{array}{l}\text { Highlight conceptual } \\
\text { differences and/or } \\
\text { similarities between } \\
\text { relationships. }\end{array}$ & $\begin{array}{l}\text { Discuss why the literature } \\
\text { should (or should not) } \\
\text { rely on a set of } \\
\text { relationships. }\end{array}$ \\
\hline Procedures & $\begin{array}{l}\text { Present a new perspective } \\
\quad \text { regarding a methodology. }\end{array}$ & $\begin{array}{l}\text { Present an integrative } \\
\text { discussion regarding } \\
\text { a methodology. }\end{array}$ & $\begin{array}{l}\text { Discuss similarities/ } \\
\text { differences between } \\
\text { methodologies. }\end{array}$ & $\begin{array}{l}\text { Discuss the pros/cons } \\
\text { of a methodology }\end{array}$ \\
\hline Domains/Discipline/Science & $\begin{array}{l}\text { Present a novel perspective } \\
\text { regarding a domain, } \\
\text { discipline, or mode } \\
\text { of scientific inquiry. }\end{array}$ & $\begin{array}{l}\text { Discuss the domain of } \\
\text { an emerging area of } \\
\text { research. }\end{array}$ & $\begin{array}{l}\text { Isolate substantive } \\
\text { differences and/or } \\
\text { similarities between } \\
\text { areas of research. }\end{array}$ & $\begin{array}{l}\text { Present a distinctive } \\
\text { point of view regarding } \\
\text { a domain, discipline, } \\
\text { or scientific inquiry. }\end{array}$ \\
\hline
\end{tabular}

Adapted from MacInnis (2011). Examples shown in the table are illustrative and not exhaustive; a broader range of conceptual contributions can be explored in each cell. Furthermore, elements from each cell can be combined to expand the scope of conceptual inquiry of an article and strengthen its contribution. For additional details regarding the four primary conceptual goals, including finer distinctions that can be made within each goal, see MacInnis (2011) 
contributions. Articles of this type may sometimes invoke elements of conceptual inquiry listed in the column labeled "Debating." Advancing a new point of view may necessitate refuting an existing, dominant perspective. In a dynamic, social science discipline such as marketing, "envisioning" and "debating" articles can play a very important role in reinvigorating knowledge development. AMS Review seeks to be a platform for this much-needed work in the marketing discipline.

\section{Looking ahead}

A journal's success in a discipline relies heavily on the investment of time and effort made by scholars in that discipline. In fact, a journal is a physical manifestation of the scholars who contribute to it, serve as reviewers, or support it in other ways. I'm very pleased that many leading scholars in our field have accepted my invitation to help build the journal and enhance its impact in our field. I have formed a four-member Advisory Board to provide strategic advice as we move forward with the journal. The four members are: O.C. Ferrell (University of New Mexico), Hubert Gatignon (INSEAD), Ajay Kohli (Georgia Institute of Technology), and Debbie MacInnis (University of Southern California). These scholars have made significant contributions to our discipline; they are also leading advocates of the need for greater focus on theory development. I'm grateful for their support and counsel. In addition to forming the Advisory Board, I have significantly expanded the Editorial Review Board (ERB) to plan for the future growth of AMS Review. The 56-member board consists of leading scholars representing all major substantive areas in the marketing discipline. Authors submitting their work to AMS Review will certainly benefit from the insights and critique of this world-class ERB. If needed, I will add more members to the ERB during my term.

In addition to serving as a leading outlet for conceptual articles, AMS Review also plans to be involved in creating a community of marketing scholars interested in theory development work. In this regard, an important new initiative that the journal plans to launch is the AMS Review Theory Forum. The Theory Forum will be an annual "signature event" that brings together leading and emerging marketing scholars to share their perspectives on theory development in marketing. Specifically, the Theory Forum will have the following objectives:

- Critically assess the state of knowledge development in marketing, with special emphasis on theoretical progress.

- Identify significant gaps with respect to theory development in various substantive domains and advance proposals for addressing these gaps.

- Discuss specific strategies and tools that marketing scholars can utilize for enhancing theory-building efforts in their research programs.

- Strengthen institutional factors (e.g., journals and doctoral programs) to reinvigorate theory development in the marketing discipline.

Over time, as the Theory Forum evolves, the journal will explore other opportunities to facilitate theory development work and discussions (e.g., creating theory development workshops for doctoral students). I hope you will be able to participate in one of these events.

As we pursue these and related initiatives, AMS Review will stay focused on its key long-term goal: to become a premier academic journal that publishes the highest quality conceptual articles in the marketing discipline. A lot of work remains to be done before that goal can be accomplished. I'm confident that, with the support of the global community of marketing scholars, this promising journal can achieve its full potential.

Acknowledgments I would like to express my appreciation for comments and suggestions from AMS Reviewś Advisory Board members (O.C. Ferrell, Hubert Gatignon, Ajay Kohli, and Debbie MacInnis).

\section{References}

Darden, L. (1991). Theory change in science. New York: Oxford University Press.

MacInnis, D. J. (2011). A framework for conceptual contributions in marketing. Journal of Marketing, 75(4), 136-154.

Reibstein, D. J., Day, G., \& Wind, J. (2009). Guest editorial: is marketing academia losing its way? Journal of Marketing, 73(4), 1-3.

Yadav, M. S. (2010). The decline of conceptual articles and implications for knowledge development. Journal of Marketing, 74(1), 1-19. 